\title{
Epidemiological study of cardiovascular risk factors among public transport drivers in rural area of Chittoor district of Andhra Pradesh
}

\author{
Sharvanan Eshwaran Udayar ${ }^{1 *}$, Shankar Sampath ${ }^{2}$, Arun D. ${ }^{1}$, Sai Sravan ${ }^{1}$
}

\author{
${ }^{1}$ Department of Community Medicine, PES Institute of Medical Sciences and Research, Kuppam, Chittor, Andhra \\ Pradesh, India \\ ${ }^{2}$ Department of Community Medicine, Chennai Medical College Hospital and Research Center, Trichy, Chennai, \\ Tamil Nadu, India
}

Received: 10 September 2015

Accepted: 21 September 2015

\section{*Correspondence:}

Dr. Sharvanan Eshwaran Udayar,

E-mail: saravananudayar83@gmail.com

Copyright: () the author(s), publisher and licensee Medip Academy. This is an open-access article distributed under the terms of the Creative Commons Attribution Non-Commercial License, which permits unrestricted non-commercial use, distribution, and reproduction in any medium, provided the original work is properly cited.

\section{ABSTRACT}

Background: Non communicable diseases (NCDs) are considered as one of the major health and development challenges of the 21 st century, recent studies had demonstrated that transport drivers are at greater risk of developing cardiovascular diseases due to an incorrect diet, sedentary behavior, unhealthy lifestyles and obesity. The objective of the study was the study was conducted with the aim of assessing some cardiovascular risk factors and its relation to sociodemographic variables.

Methods: Cross sectional study was carried out from Jan 2013 to June 2013 with transport drivers of APSRTC of Venkatagiri Kota. Data was collected regarding socio-demographic profile, diabetes, use of medication, tobacco and alcohol consumption, work schedules and perceived occupational problems and their blood pressure and anthropometry were also measured \& analyzed using SPSS software.

Results: 204 transport drivers were studied. Out of95 tobacco consumers 68 were smokers and 27 were tobacco chewers and 110 subjects were alcohol consumers. Perceived reasons for smoking were it suppresses cold (27.94\%) and enables to concentrate on work $(20.58 \%)$. Perceived reasons for alcohol consumption were peer pressure $(17.2 \%)$ and it suppresses cold (20\%). Among 204 subjects 36.2\% were pre-obese and $34.8 \%$ were obese with $23.05 \%$ of prehypertensive and $14.21 \%$ hypertensive. Duration of alcohol intake and tobacco use, BMI, WHR \& WC were significantly associated with hypertension.

Conclusions: There is a high prevalence of risk factors of cardiovascular disease with various perceived reasons and they were statistically significantly associated with hypertension.

Keywords: BMI, Venkatagiri Kota, Cardiovascular, Risk Factors, Transport drivers

\section{INTRODUCTION}

Non communicable diseases (NCDs) are considered as one of the major health and development challenges of the 21 st century, in terms of both the human suffering they cause and the harm they inflict on the socioeconomic fabric of countries, particularly low- and middle-income countries.
It is said that governments cannot afford to ignore the rising burden of NCDs. In the absence of evidence-based actions, the human, social and economic costs of NCDs will continue to grow and will have a devastating consequences particularly in poor and vulnerable populations.

In today's scenarios as the leading cause of death globally, NCDs comprising mainly of cardiovascular 
diseases, cancers, diabetes and chronic lung diseases were responsible for 38 million $(68 \%)$ of the world's 56 million deaths in 2012. More than $40 \%$ of them (16 million) were premature deaths under age 70 years. Almost three quarters of all NCD deaths (28 million), and the majority of premature deaths $(82 \%)$, occur in lowand middle-income countries.

Obesity increases the likelihood of diabetes, hypertension, coronary heart disease, stroke and certain types of cancer. Worldwide, the prevalence of obesity has nearly doubled since 1980 . In $2014,11 \%$ of men and $15 \%$ of women aged 18 years and older were obese. ${ }^{1}$

It is well known fact that the NCDs are caused, to a large extent, by four behavioural risk factors that are pervasive aspects of economic transition, rapid urbanization and 21st-century lifestyles: tobacco use, unhealthy diet, insufficient physical activity and the harmful use of alcohol $^{2}$.

Many studies have demonstrated that there is a strong correlation between risk factors of cardiovascular diseases and the occupational factors.,

Changes in working condition, extreme overwork and job stress due to being chronically overworked for long period are considered as main triggering factors for cardiovascular diseases such as myocardial infarction and stroke. ${ }^{5-8}$

Workers in the transportation industry are at greater risk of an incorrect diet and sedentary behaviour. Professional drivers, in particular, have higher mortality, morbidity, and absenteeism rates due to obesity. Hypertension is one of the main outcome of this disease and is common among professional drivers. ${ }^{9}$

Public transport drivers who carry passengers are at greater risk than those who carry goods. ${ }^{10,11}$ It is estimates that the number of deaths due to traffic accidents will increase by $65 \%$ between the years 2000 and 2020, with this figure expected to be as high as $80 \%$ in developing countries. $^{12}$

The study was conducted with the objective of assessing some cardiovascular risk factors and its relation to sociodemographic variables.

\section{METHODS}

A cross sectional study was carried out from Jan 2013 to June 2013 for a period of 6 months, involving a population transport drivers working in Andhra Pradesh State Road Transport Corporation (APSRTC) in the town of Venkatagirikota mandal of Chittoor District, Andhra Pradesh state.

Those who were permanent residents since one year were included in the study. Data was collected from the subjects by administering semi structured questionnaire. And they were examined during the official working hours (10am to $5 \mathrm{pm}$ ) with regard to sociodemographic profile and anthropometric characteristics (weight, height, body mass index (BMI), abdominal circumference), systolic and diastolic blood pressure. Self-history, use of medication and lab report of diabetes was included in collecting the data. Blood pressure was measured at rest with the subject remaining seated for 10 minutes and the average of the two readings was taken into consideration for classification according to World Health Organization (WHO). ${ }^{13}$ Approval was obtained from the Institutional Ethical Committee. Informed consent was obtained from the study participants after explaining the purpose of the study.

\section{Anthropometric measurements}

Calibrated balance beam scale was used to measure weight in the upright position to the nearest

$0.1 \mathrm{~kg}$. Height was measured with bare foot to the nearest $0.1 \mathrm{~cm}$ using calibrated Stadiometer. Body mass index (BMI) was calculated by dividing observed weight by height squared $(\mathrm{kg} / \mathrm{m} 2)$. Waist hip ratio was calculated by measuring waist and hip circumferences. Waist circumference (WC) was measured to the nearest $0.1 \mathrm{~cm}$ at the midpoint between lower end of the rib cage and iliac crest. Hip circumference was measured to the nearest $0.1 \mathrm{~cm}$ at the greatest horizontal circumference below the iliac crest at the level of greater trochanter. BMI was classified using the method stipulated by the World Health Organization for South Asians. ${ }^{14,15}$ And Waist Hip ratio was classified according to Report of a WHO Expert Consultation. ${ }^{16}$

Table 1: Mean and standard deviation (SD) for various cardiovascular disease risk factors.

\begin{tabular}{|l|ll|}
\hline Variables & Mean & \pm SD \\
\hline Age $($ years $)$ & 41.38 & 10.45 \\
\hline Height $(\mathrm{cm})$ & 164.03 & 4.74 \\
\hline Weight $(\mathrm{kg})$ & 68.80 & 15.75 \\
\hline Body mass index $(\mathrm{kg} / \mathrm{m} 2)$ & 26.93 & 4.18 \\
\hline Waist circumference $(\mathrm{cm})$ & 89.85 & 10.41 \\
\hline Hip circumference $(\mathrm{cm})$ & 94.13 & 8.47 \\
\hline Waist /hip ratio & 0.97 & 0.08 \\
\hline Systolic blood pressure $(\mathrm{mmHg})$ & 120.33 & 14.44 \\
\hline Diastolic blood pressure $(\mathrm{mmHg})$ & 80.18 & 11.39 \\
\hline
\end{tabular}

Hypertension was defined as systolic blood pressure (SBP) of $\geq 140 \mathrm{mmHg}$ or diastolic blood pressure (DBP) $\geq 90 \mathrm{mmHg}$ as per WHO criteria or history of previously known disease and pre-hypertension was defined as SBP 120-139 $\mathrm{mmHg}$ or DBP 80-89 mmHg. Self-reported history of previously known disease was included in the questionnaire. 
With regard to behavioural risk factors, tobacco questionnaire included data on self-reported duration, frequency and quantity of tobacco consumption. Individuals were classified as exsmoker, current smoker and smokeless tobacco product consumer. Current daily smokers were defined as those who were currently smoking tobacco daily in the form of cigarettes, bidis (hand-manufactured cigarettes consisting of tobacco wrapped in a temburini leaf), hookah (Indian water pipe), chillum, or any other smoked form. Similarly, current daily smokeless tobacco users were defined as those who were currently using chewable tobacco products: khaini (tobacco-lime mixtures), gutkha (tobacco with betel nut, catechu, lime, and flavourings), naswar (snuff), or zarda paan (betel quid with tobacco) daily. ${ }^{17}$

Table 2: Distribution of study subjects according to their body mass index $(n=244)$.

\begin{tabular}{|lll|}
\hline Body mass index $\left(\mathrm{kg} / \mathrm{m}^{2}\right)$ & nor. & Percentage \\
\hline Underweight $(<18.5)$ & 3 & 1.5 \\
\hline Normal $(18.5-23)$ & 56 & 27.5 \\
\hline Pre Obese $(23-27.5)$ & 74 & 36.2 \\
\hline Obese $(>27.5)$ & 71 & 34.8 \\
\hline Total & 204 & 100 \\
\hline
\end{tabular}

Self-reported alcohol intake data was collected and subjects were classified as current consumer, past consumer and not a consumer. Current alcohol users were those who had consumed alcohol at least once during the past one year preceding the time of the interview whereas past users were defined as persons who had consumed alcohol at least once during their lifetime but had not done so for a period of one year preceding the survey. ${ }^{18}$ After the medical examination employees completed a semi structured questionnaire assessing their work schedules, personal habits (health and job related), selfperceptions about specific occupational problems. Statistical tests like mean, standard deviation, percentage, proportion and Chi-square were applied by using SPSS software package $19^{\text {th }}$ version.

\section{RESULTS}

Table 3: Distribution of study subjects according to their blood pressure $(n=244)$.

\begin{tabular}{|lll|}
\hline Blood pressure levels & nor. & $\%$ \\
\hline Normal & 128 & 62.74 \\
\hline Pre hypertensive & 47 & 23.05 \\
\hline Stage 1 & 24 & 11.76 \\
\hline Stage2 & 05 & 2.45 \\
\hline Total & 204 & 100 \\
\hline
\end{tabular}

\section{Socio-demographic characteristics}

A total of 204 male transport drivers were studied. Mean age of study subjects was $41.38 \pm 10.45$ yrs. with a range of $20-60$ yrs. $38.72 \%$ subjects were above 45 years of age. $177(86.76 \%)$ subjects were ever married. 121 $(59.31 \%)$ subjects belonged to nuclear family. 74 $(36.27 \%)$ subjects had secondary education; while 102 (50\%) had primary education. 145 (71.4\%) subjects belonged to upper and middle socio-economic class according to modified BG Prasad classification while 59 (28.6\%) belonged to lower class. ${ }^{19}$ Mean length of occupation was $19.00 \pm 7.63$ years with a range of 1-35 years; while average daily working hours was $10.52 \pm 2.29$ with a range of 6-17 hours. Mean and Standard Deviation (SD) of various risk factors is given in Table 1.

Table 4: Association between cardiovascular risk factors and hypertension.

\begin{tabular}{|c|c|c|c|c|}
\hline \multirow[t]{2}{*}{$\begin{array}{l}\text { Alcohol } \\
\text { intake (yrs.) }\end{array}$} & \multicolumn{2}{|c|}{$\begin{array}{l}\text { (Hypertension + } \\
\text { prehypertension) }\end{array}$} & \multirow[t]{2}{*}{$\begin{array}{l}\text { Chi- } \\
\text { Square }\end{array}$} & \multirow[t]{2}{*}{$\mathbf{P}$} \\
\hline & Yes & No & & \\
\hline$<5$ & 03 & 11 & & \\
\hline $6-10$ & 09 & 11 & \multirow{4}{*}{8.18} & \multirow{4}{*}{0.04} \\
\hline $11-20$ & 31 & 25 & & \\
\hline$>20$ & 13 & 07 & & \\
\hline \multicolumn{3}{|l|}{$\begin{array}{l}\text { Tobacco use } \\
\text { (yrs.) }\end{array}$} & & \\
\hline$<5$ & 24 & 3 & \multirow{4}{*}{16} & \multirow{4}{*}{0.001} \\
\hline $6-10$ & 11 & 5 & & \\
\hline $11-20$ & 17 & 5 & & \\
\hline$>20$ & 12 & 18 & & \\
\hline \multicolumn{3}{|l|}{$\begin{array}{l}\text { Extra salt } \\
\text { intake }\end{array}$} & & \\
\hline Yes & 17 & 35 & \multirow{2}{*}{0.4} & \multirow{2}{*}{0.52} \\
\hline No & 59 & 93 & & \\
\hline \multicolumn{5}{|l|}{ BMI } \\
\hline $\begin{array}{l}\text { Normal+ } \\
\text { Underweight }\end{array}$ & 16 & 43 & \multirow{3}{*}{11.6} & \multirow{3}{*}{0.003} \\
\hline PreObese & 23 & 53 & & \\
\hline Obese & 37 & 32 & & \\
\hline \multicolumn{5}{|l|}{$\begin{array}{l}\text { Waist Hip } \\
\text { Ratio }\end{array}$} \\
\hline$>0.9$ & 57 & 49 & \multirow{2}{*}{25.8} & \multirow{2}{*}{0.000} \\
\hline$<0.9$ & 19 & 79 & & \\
\hline \multicolumn{5}{|l|}{$\begin{array}{l}\text { Waist } \\
\text { circumference }\end{array}$} \\
\hline$>90 \mathrm{~cm}$ & 42 & 50 & \multirow{2}{*}{5.05} & \multirow{2}{*}{0.002} \\
\hline$<90 \mathrm{~cm}$ & 34 & 78 & & \\
\hline
\end{tabular}

\section{Personal habits/addictions}

95(46.56\%) subjects had habit of tobacco consumption out of which 68 were current tobacco smokers and 27 had habit of tobacco chewing, 58 subjects started the habit of tobacco consumption after joining the job. 17 (7.76\%) had habit of Gutkha chewing. Average duration of tobacco smoking was $12.42 \pm 7.41$ years and the average number of tobacco smoking in the form of Cigarettes/Bidis/Others was 6.02 times a day. 
Of the total 110 alcohol consumers, the average duration of alcohol consumption was $18.23 \pm 7.08$ years. Average amount of alcohol consumed per session was $173.30 \pm 68.37 \mathrm{ml} .17 .27 \%$ of the subjects were consuming alcohol on a 'daily' basis, while $17.83 \% \%$ were taking it on an 'alternate day' basis and $43 \%$ were consuming alcohol on 'weekly' basis. 45 out of total 110 alcohol consumers started the habit after joining the job. Various reasons for starting habit of smoking and alcohol consumption is given in Figure 1 and 2.

$22.05 \%$ of transport drivers had opinion that their job is a mentally challenging one. The reasons were driving in congested road (13) aggressive passengers (11) night shifts (10) weekend shifts (7) lack of leisure time (4).

$26(12.7 \%)$ subjects were engaged in regular physical exercise while $178(87.3 \%)$ were not engaged in any sort of physical exercise. $6.27 \%$ of the transport drivers also reported a family history of diabetes. With regard to dietary factors $118(57.8 \%)$ drivers had a regular habit of eating outside food when they are on duty. 51 (25.0\%) of drivers also gave history of extra salt consumption in the form of pickle, pappad, dry fish etc.

\section{Weight, height and body mass index}

Table 3 shows the distribution of subjects according to their body mass index (BMI). Mean body mass index (BMI) of 56(27.4\%) subjects was found to be in normal range $\left(18.50-23 \mathrm{~kg} / \mathrm{m}^{2}\right)$; while $\mathrm{BMI}$ of $71(34.8 \%)$ subjects was in Obese range $\left(>27.5 \mathrm{~kg} / \mathrm{m}^{2}\right)$. It was also observed that $3(1.5 \%)$ subjects were under-weight (BMI $\left.<18.5 \mathrm{~kg} / \mathrm{m}^{2}\right), 74(36.2 \%)$ subjects were pre obese (BMI= $\left.23-27.5 \mathrm{~kg} / \mathrm{m}^{2}\right)$.

\section{Blood pressure}

Table 4 shows the distribution of study subjects according to their blood pressure (BP) levels. 128 $(62.74 \%)$ subjects were found to have normal blood pressure levels while $47(23.03 \%)$ subjects had prehypertension and 29 (14.21\%) subjects had hypertension. Among hypertensives $11.76 \%$ and $3.28 \%$ had grade I and grade II hypertension respectively.

$27.2 \%$ of the transport drivers also reported a family history of hypertension. Central obesity using WHR criteria $(>0.90)$ and WC criteria $(\geq 90 \mathrm{~cm})$ was present in $106(51.96 \%)$ and $92(45.09 \%)$ and subjects respectively. It was also found out that only $20(8.2 \%)$ of transport drivers self-reported the history of diabetes.

With respect to association between hypertension and various risk factors as depicted in table 5, statistically significant association was found between duration of alcohol intake, duration of tobacco use, body mass index, waist hip ratio and waist circumference, whereas association between extra salt intake and hypertension was not statistically significant.

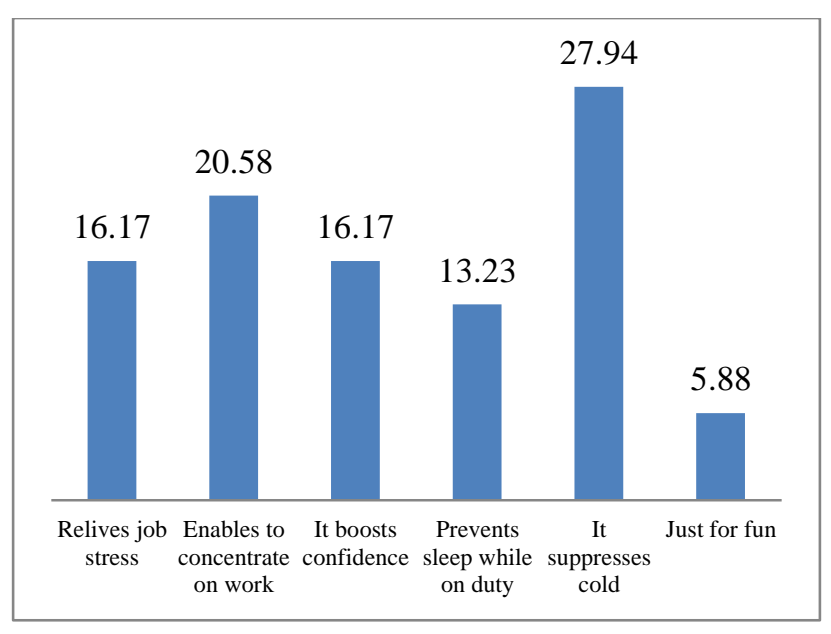

Figure 1: Perceived reasons for tobacco smoking $\mathrm{n}=68(100 \%)$.

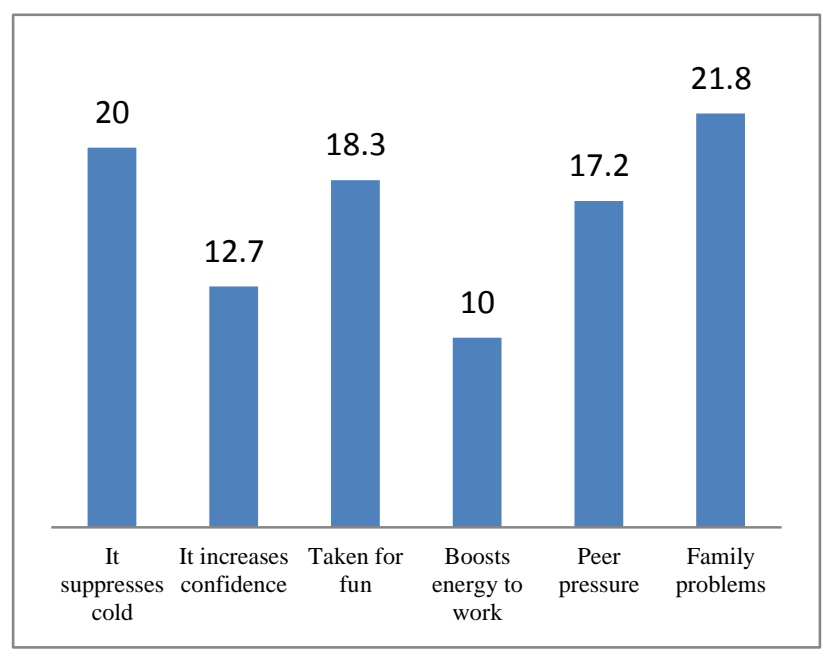

Figure 2: Perceived reasons for alcohol consumption $\mathrm{n}=110(\mathbf{1 0 0 \%})$.

\section{DISCUSSION}

Public transport drivers are one of the important high risk groups who are at risk of increased morbidity and mortality associated with cardiovascular diseases. Factors like unhealthy behavioural and lifestyle factors form a major portion of the problem. Our study results showed that there is a high prevalence of behavioural risk factors, central obesity and hypertension among male transport drivers and these risk factors increased during the most productive years (25-44 yrs.) putting them at risk of cardiovascular morbidity and mortality at relatively younger age. Our study also made an attempt to study the influence of behavioural and lifestyle transition on the prevalence of cardiovascular risk factors. Higher prevalence of tobacco consumption was seen in our study subjects, the findings were similar to the study by Per Gustavsson et al. ${ }^{20}$ Prevalence of smoking (33.3\%) and hypertension $(14.21 \%)$ and obesity $(34.8 \%)$ were comparable with the studies done by Kartikeyan $\mathrm{S}$ et al, Kobayashi $\mathrm{F}$ et al, Tveito TH. ${ }^{21-23}$ 
Similar finding were reported by Zulkifle MD with respect to the prevalence of hypertension (14.02\%) based on a study done among Bangalore Metropolitan Transport Corporation (BMTC) Employees. ${ }^{24}$ However in the present study the prevalence was less than the reported national prevalence of $25 \% .^{25,26}$ Our study results are consistent with the cross sectional analytical study done on professional drivers who worked with heavy vehicles in the city of Yazd. ${ }^{27}$

\section{CONCLUSION}

In our study statistically significant association between hypertension and obesity based on BMI criteria and waist-hip ratio more than 0.9 was also obtained but not with physical activity. Although one quarter of the study population were consuming extra salt, this was not statistically significant with respect to hypertension this may be due to subjective reporting of salt intake which is inaccurate and not estimating the salt intake by 24-h urinary sodium excretion method as per WHO guidelines ${ }^{28}$. Although diabetes is a different clinical entity, the presence of both hypertension and diabetes will increase the risk of morbidity and mortality by several folds. In this study, there was no significant association between diabetes and hypertension, this might be due to reasons like small sample size and only history of diabetes was elicited through questionnaire and no diagnostic modalities were employed. Most of the study subjects were unaware whether they are diabetic or nondiabetic individuals. A larger sample with laboratory confirmation of the presence or absence of diabetes could have given better information regarding the association between diabetes and hypertension.

People employed in the transport sector form a considerable workforce of our nation. Intersectoral coordination between transport department and health department is needed to protect and promote the health of transport employees. Thorough pre-placement and periodical examinations are to be conducted and necessary steps are to be taken. Regular health education programmes are to be conducted regarding various noncommunicable diseases and attendance to such programmes should be made compulsory. Strict guidelines about diet are to be formulated and implemented in all the eateries catering to the employees. Various recreational facilities, counselling centres with psychologists are to be established in all the depots to help the employees cope with their stress.

Funding: No funding sources

Conflict of interest: None declared

Ethical approval: The study was approved by the Institutional Ethics Committee

\section{REFERENCES}

1. World Health Organization. Global status report on non-communicable diseases 2014. Available at: http://www.who.int/nmh/publications/ncd-statusreport-2014/en/. Accessed 16 Jul 2015.

2. Sharvanan EU, Konduru RK, Praveen BA Pawan K, sivachandiran V, Srinivas T. Study of cardiovascular risk factors among transport drivers in rural area of Andhra Pradesh. Intl J Res Health Sci. 2014;2(1):420-6.

3. Buring JE, Evans DA, Fiore M, Rosner B, Hennekens $\mathrm{CH}$. Occupation and risk of death from coronary heart disease.J Am Med Assoc. 1987;258:791-2.

4. Tüchsen F, Andersen O, Costa G, Filakti H, Marmot MG. Occupation and ischemic heart disease in the European community: a comparative study of occupations at potential high risk. Am J Ind Med. 1996;30:407-14.

5. Shin SY, Lee CG, Song HS, Kim SH, Lee HS, Jung MS, et al. Cardiovascular Disease Risk of Bus Drivers in a City of Korea. Ann Occ Env Med. 2013;25-34.

6. Malinauskiene V.Truck driving and risk of myocardial infarction. Przegl Lek. 2003;60(Supp16):89-90.

7. Bigert $\mathrm{C}$, Klerdal $\mathrm{K}$, Hammar $\mathrm{N}$, Hallqvist J, Gustavsson P.Time trends in the incidence of myocardial infarction among professional drivers in Stockholm 1977-96. Occu Env Med. 2004;61(12):987-91.

8. Wang PD, Lin RS. Coronary heart disease risk factors in urban bus drivers. Public Health. 2001;115(4):261-4.

9. Hirata RP, Sampaio LMM, Leitão Filho FSS, Branhiroli A, Balbi B, Romano S, et al. General characteristics and risk factors of cardiovascular disease among interstate bus drivers. Sci World J. 2012;2012(4):1-7.

10. Tüchsen F, Hannerz H, Roepstorff C, Krause N. Stroke among male professional drivers in Denmark, 1994-2003. Occ Env Med. 2006;63(7):456-60.

11. Hannerz H, T"uchsen F. Hospital admissions among male drivers in Denmark. Occ Env Med. 2001;58(4):253-60.

12. World Health Organization. World Report on road traffic injury prevention 2004. Available at: http://www.who.int/violence_injury_prevention/pub lications/road_traffic/world_report/summary_en_rev .pdf . Accessed 16 Jul 2015.

13. Whitworth JA. World Health Organization, International Society of Hypertension Writing Group. Statement on management of Hypertension. J Hyperten. 2003;21:1983-92.

14. World Health Organization. Obesity- Preventing and managing the global epidemic. WHO technical report series 894, 1999. Available at: http://www.who.int/nutrition/publications/obesity/W HO_TRS_894/en/. Accessed 16 Jul 2015.

15. World Health Organization, Western Pacific Region. The International Association for the Study of Obesity and the International Obesity Task Force. 
The Asia-Pacific perspective: redefining obesity and its treatment. Sydney, Australia: Health Communications Australia Pty Limited, 2000.

16. World Health Organization. The atlas of heart disease and stroke 2004. Available at: http://www.who.int/cardiovascular_diseases/resourc es/atlas/en/. Accessed 16 Jul 2015.

17. Gupta V, Yadav K, Anand K. Patterns of Tobacco Use across Rural, Urban, and Urban-Slum Populations in a North Indian Community. Ind $\mathbf{J}$ Com Med. 2010;35(2):245-51.

18. Goswami A, Reddaiah VP, Kapoor SK, Singh B, Dwivedi SN, Kumar G. Tobacco and alcohol use in rural elderly Indian population. Ind $\mathbf{J}$ Psych. 2005;47(4):192-7.

19. All India Consumer Price Index (General) for Industrial Workers, 2013. http://cyberjournalist.org.in/manisana/aicpinew.html . Accessed 13 Dec 2014.

20. Gustavsson P, Alfredsson L, Brunnberg H, Niklas $\mathrm{H}$, Robert J, Christina R ,et al. Myocardial infarction among male bus, taxi, and lorry drivers in middle Sweden,Occup Env Med. 1996;53:235-40.

21. Kartikeyan S ,Gurav R, Joshi SD, Wayal R. Health and Socio-Demographic Profile of Transport Workers. Ind J Occ and Env Med. 2004;8(2):8-10.

22. Fumio K, Takemasa W, Misuzu W, Yasuhiro A, Teruyuki $\mathrm{T}$, Taisuke $\mathrm{N}$, et al.Blood pressure and heart rate variability in taxi drivers on long duty schedules. J Occup Hea. 2002;44:214-20.
23. Tveito TH, Odeen M, Eriksen HR. Myths about lifestyle and health of taxi drivers: true or false? Occup Env Med. 2005;62:e10.

24. Mohd. Z, Abdul HA, Mohd. S, Mohd. A. Hypertension Scenario in Bangalore Metropolitan Transport Corporation (BMTC) Employees - A Study. Intl J Adv Ayu, Yog, Una, Sid Hom. 2012;1(1):1-5.

25. Gupta R, Gupta VP, Sarna M, Bhatnagar S, Thanvi J, Sharma V, et al. Prevalence of Coronary Heart Disease and Risk Factors in an Urban Indian Population: Jaipur Heart Watch-2. Ind Heart J. 2002;54(1):59-66.

26. Gupta R, Sarna M, Thanvi J, Rastogi P, Kaul V, Gupta VP, et al. High Prevalence of Multiple Coronary Risk Factors in Punjabi Bhatia Community: Jaipur Heart Watch-3. Ind Heart J. 2004;56(6):646-52.

27. Seyed mehdi SM, Dehghan F, Mohammadi S, Attarchi MS. Assessment of ischemic heart diseases and related risk factors in professional drivers. Ira Occup H. 2010;7(3):1-8.

28. World Health Organization. Forum on Reducing Salt Intake in Populations. Available at http://www.who.int/dietphysicalactivity/reducingsalt intake_EN.pdf. Accessed 13 Jul 2015.

Cite this article as: Udayar SE, Sampath S, Sai Sravan AD. Epidemiological Study of cardiovascular risk factors among public transport drivers in rural area of Chittoor district of Andhra Pradesh. Int J Community Med Public Health 2015;2:415-20. 